\title{
$\underline{\text { Thomas Jefferson Visitor Center and Smith Education Center at Monticello }^{1}}$
}

Methodology for Landscape Performance Benefits

Case Study Investigation 2014

University of Virginia

Research Fellow:

Leena Cho

Lecturer in Landscape Architecture

School of Architecture, University of Virginia

Research Assistant:

Margaret Graham, MLA Candidate

School of Architecture, University of Virginia

Firm Liaison:

Michael Vergason Landscape Architects

Michael Vergason, Principal

Rob Holmes, Landscape Architect

\footnotetext{
${ }^{1}$ This white paper can be cited as: Cho, Leena, and Margaret Graham. "Thomas Jefferson Visitor Center and Smith Education Center at Monticello Case Study Methodology." Landscape Architecture Foundation. 2014.
} 
The Thomas Jefferson Visitor Center in Charlottesville, completed in 2008, occupies 13 acres at the base of Monticello's mountaintop setting. Costing $\$ 5.4$ million for all site work, the project provides a whole new visitor experience for those visiting this World Heritage site. This case study examines the efforts to embed the project into the surrounding woodland setting while also minimizing the environmental impact that this large-scale development produces in stormwater runoff. The case study was greatly enhanced by the figures that Monticello was able to provide regarding visitor experience and records of facts and figures.

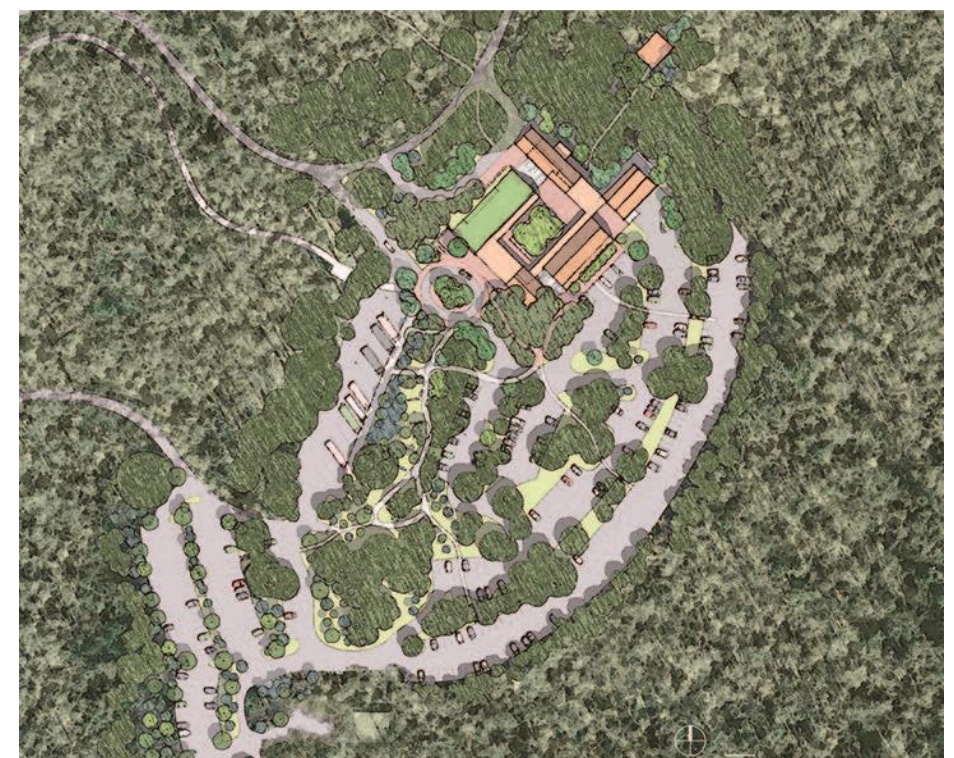

Figure 1. Visitor Center site plan identifying building site: the Source: MVLA Visitor Center building and parking area

\section{Environmental Performance Benefits:}

- Captures and treats $90 \%$ of average annual rainfall of building site. The vegetated swales, green roofs, underground stormwater storage, vegetated bioretention gardens, and retention pond are designed to manage up to a 10-year storm

Method: Data was extracted from LEED documentation provided by MVLA and RK\&K engineers. Engineers designed for a 10-year storm according to Albemarle County regulations.

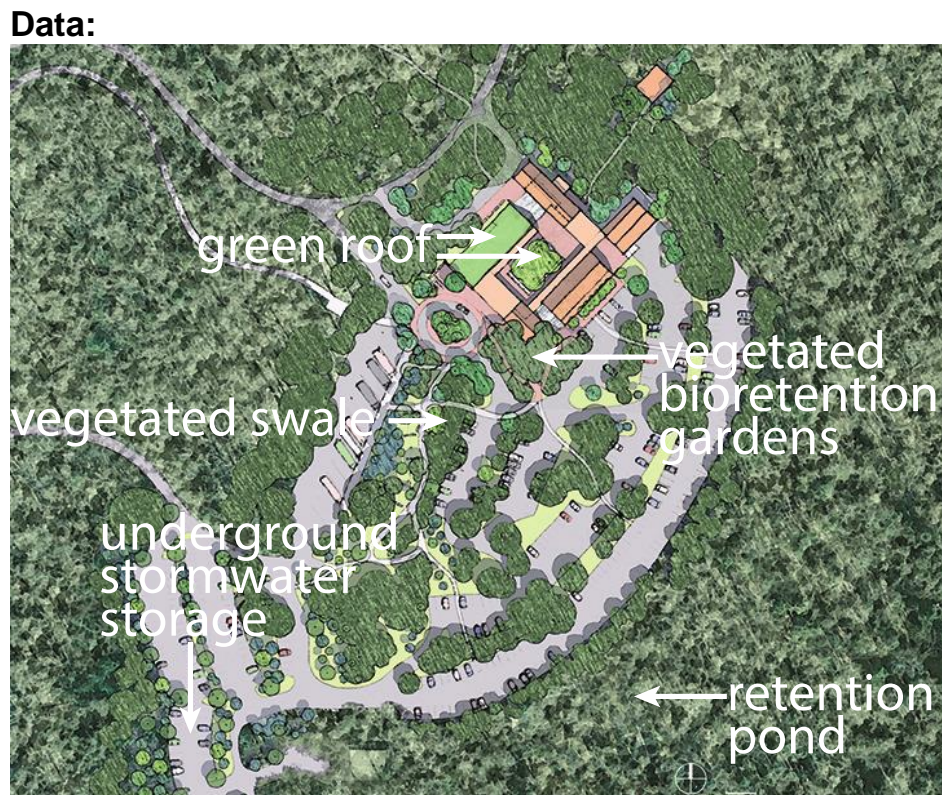


Figure 2. Siteplan identifying scope of the building site and BMP features

Source: adapted from MVLA siteplan

Limitations: Records and calculations do not identify which BMP features are responsible for what percentage of capturing and treating rainfall and therefore the calculations are representative of all of the features collectively.

References:

Thomas Jefferson Visitor Center LEED-NC: Construction Application Review. : U.S. Green Building Council, 2009.

- Estimated to remove $80 \%$ of total suspended solids from the captured runoff.

Method: Data was extracted from LEED documentation provided by MVLA and RK\&K engineers.

Limitations: Data was calculated based on standards of BMP features as opposed to on-site measurements.

References:

Thomas Jefferson Visitor Center LEED-NC: Construction Application Review. : U.S. Green Building Council, 2009.

- Reduces potable water consumption for irrigation by 292,700 gallons or 63\% compared to a baseline case by utilizing water-efficient plantings. This saves $\$ 1,770$ annually.

Method: Data was extracted from LEED WE1.1 documentation provided by MVLA and RK\&K engineers. LEED requires $50 \%$ reduction to receive 1 point, and this project exceeds that standard by $12.3 \%$.

Data:

Irrigation Cost Savings

\begin{tabular}{|l|r|}
\hline Baseline Case (July) & $132,560.7 \mathrm{gal}$ \\
\hline Design Case (July) & $49,927.6 \mathrm{gal}$ \\
\hline Savings (July) & $82,633.1 \mathrm{gal}$ \\
\hline Typical irrigation cycles (July) & 24 \\
\hline Average water savings per cycle & $3,443 \mathrm{gal}$ \\
\hline Total typical cycles per year & 85 \\
\hline Total average water savings/year & $292,659 \mathrm{gal}$ \\
\hline $\begin{array}{l}\text { Total average water savings/year } \\
\text { (1000 gal) }\end{array}$ & 293 \\
\hline Cost/1000 gal & $\$ 6.04$ \\
\hline Annual cost savings & $\$ 1,767.66$ \\
\hline
\end{tabular}

Limitations: This calculation is in comparison to a baseline case and may not fully represent the actual cost savings as experienced by the client. Additionally, according to the LEED documentation: "Though we are pursuing/documenting only one point under WE1.1 (50\% reduction), via the compliance path 'Option 1', we would like to note that a significant portion of our site treatment complies with 'Option 4', landscaping installed does not require permanent irrigation systems/complete elimination of permanent 
irrigation systems. These areas have been omitted from our water use calculations, since there was not a compliance option combining the strategies of reduction and partial elimination. We request that in future revisions to this template, a combination of these strategies might be permitted." Therefore, quantified savings would be higher by including areas that qualify for "Option 4."

\section{References:}

Michael Vergason Landscape Architects, Ltd. "Irrigation Cost Savings." 2009.

Michael Vergason Landscape Architects, Ltd. "LEED-NC 2.2 Submittal Template WE Credit 1: Water Efficient Landscaping." LEED-NC. 2009.

- Reduces average summer air temperatures by $1.4^{\circ} \mathrm{F}$ and surface temperature by 26.5 ${ }^{\circ}$ on the gift shop green roof as compared to the adjacent hardscape. In the central courtyard, air and surface temperatures are $1.4^{\circ} \mathrm{F}$ and $29.7^{\circ} \mathrm{F}$ lower under the shade structure and trees.

Method: The research team took temperature measurements on June 16, 2014. The Kestrel 3000 was used for air temperature measurements and the Raytek Raynger ST for spot temperatures. The calculations for the meadow-covered green roof on top of the gift shop pavilion are a comparison between temperatures above the vegetation and the darker materials bordering and adjacent to it: stone, asphalt and concrete. The calculations for the central courtyard area are a comparison between the shaded areas (provided by the slatted roofs and four honey locust trees) and the uncovered areas most exposed to the sun. The two different comparisons best represent the intentions behind each green roof as designed by the landscape architect.

\section{Data:}

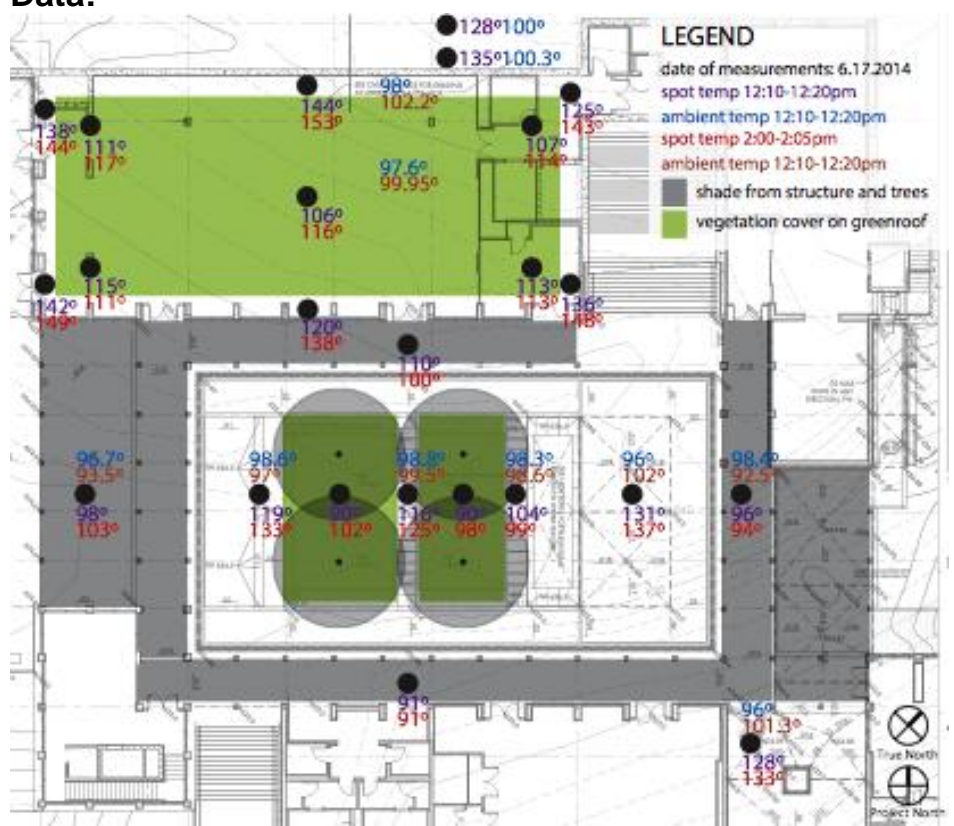

Figure 3. Comparative temperature measurements of the Visitor Center greenroofs Source: Base drawing adapted from MVLA construction drawings

Limitations: Data was collected over two hours on one summer day, and therefore variations are likely if research timeframe had allowed for more frequent measurements. 


\section{Social Performance Benefits:}

- Contributed to an increase in visitors attending special events from 3,300 in 2009 when the Visitor Center opened to 12,500 in 2013. Since 2010, 68 events hosting 9,525 people have included the outdoor spaces as their venue.

Method: Using data from the Thomas Jefferson Foundation, the research team broke down the annual events to evaluate the increase in events and attendees since the completion of the Visitor Center and also to extract information specific to the use of the outdoor spaces.

Data:

\begin{tabular}{|l|r|r|r|r|r|r|}
\hline Visitor Center Events & \multicolumn{1}{|c|}{2010} & \multicolumn{1}{|c|}{2011} & \multicolumn{1}{|c|}{2012} & \multicolumn{1}{c|}{2013} & \multicolumn{1}{c|}{ Total } \\
\hline Courtyard events & 7 & 8 & 3 & 8 & 4 & \\
\hline Courtyard people & 1,620 & 630 & 425 & 356 & 1,300 & \\
\hline Courtyard + Theater events & 3 & 7 & 10 & 8 & 8 & \\
\hline Courtyard + Theater people & 550 & 690 & 1,295 & 1,430 & 1,121 & \\
\hline Outdoor Dining events & 0 & 1 & 0 & 0 & 1 & \\
\hline Outdoor Dining people & 0 & 8 & 0 & 0 & 100 & \\
\hline Total \# Events & 10 & 16 & 13 & 16 & 13 & $\mathbf{6 8}$ \\
\hline Total \# People & 2,170 & 1,328 & 1,720 & 1,786 & 2,521 & $\mathbf{9 , 5 2 5}$ \\
\hline
\end{tabular}

Source: Thomas Jefferson Foundation

Limitations: Some events are not recorded consistently year to year. For example, the Heritage Harvest Festival is an annual event that is likely to use the outdoor spaces of the Visitor Center, but an estimated people count (4000 people) was only included in their records for 2012, and was therefore not counted because it would skew the general trends of the rest of the events. However, if there were a record of the Heritage Harvest Festival annual attendance, the overall amount of event attendees would increase.

References:

Thomas Jefferson Foundation. Special Events List of the Thomas Jefferson Visitor Center. Charlottesville: 2014.

\section{- Contributed to a one-hour increase in length-of-stay for the average annual 440,000 visitors since the completion of the Visitor Center and its landscape.}

Method: Data was extracted from reports provided by the Thomas Jefferson Foundation. According to the Thomas Jefferson Foundation, "Visitation at Monticello has been relatively stable (around 440,000 a year). In any given year, visitation can vary by $1-2 \%$. Weather is a major factor. More interesting perhaps than the raw number of visitors each year is the enhanced quality of the visit. Since the opening of the Visitor Center in 2009, our surveys show that visitors are staying one or two hours longer and visitors feel that the price they paid for admission is a good value."

Data:

Yearly attendance at Monticello

\begin{tabular}{|l|l|}
\hline 2008 & 447,514 \\
\hline 2009 & 451,816 \\
\hline 2010 & 444,957 \\
\hline 2011 & 444,100 \\
\hline 2012 & 435,888 \\
\hline 2013 & 438,002 \\
\hline
\end{tabular}

Source: Thomas Jefferson Foundation

Length of Stay 


\begin{tabular}{|l|r|r|r|r|r|r|}
\hline Length of Stay & 2009 (Jan-Apr) & 2009 (Apr-Aug) & 2010 (Jan-May) & 2011 & 2012 & 2013 \\
\hline$<1$ hour & $0.3 \%$ & $0.2 \%$ & $0.5 \%$ & & & \\
\hline $1-2$ hour & $28.3 \%$ & $6.1 \%$ & $7.3 \%$ & $12.0 \%$ & $11.0 \%$ & $12.0 \%$ \\
\hline $2-3$ hour & $52.3 \%$ & $31.1 \%$ & $31.1 \%$ & $35.0 \%$ & $35.0 \%$ & $37.0 \%$ \\
\hline $3-4$ hour & $14.2 \%$ & $37.5 \%$ & $37.0 \%$ & $28.0 \%$ & $28.0 \%$ & $29.0 \%$ \\
\hline $4-5$ hour & $3.9 \%$ & $17.9 \%$ & $16.8 \%$ & $15.0 \%$ & $15.0 \%$ & $14.0 \%$ \\
\hline $5-6$ hour & $1.0 \%$ & $5.0 \%$ & $5.6 \%$ & $6.0 \%$ & $6.0 \%$ & $6.0 \%$ \\
\hline $6+$ hour & $0.1 \%$ & $2.1 \%$ & $2.1 \%$ & $5.0 \%$ & $5.0 \%$ & $3.0 \%$ \\
\hline
\end{tabular}

Source: Thomas Jefferson Foundation

Limitations: There are many factors that affect the number of visitors at Monticello and their length of stay. These include weather, length of time between the guest's arrival and their scheduled house tour, time of year, size of group, etc... Therefore, it is difficult to attribute any increases to the Visitor Center, although all visitors experience the courtyard during their visit.

\section{References:}

Thomas Jefferson Foundation. Overall Visitor Satisfaction Index. Charlottesville: 2014.

\section{- Creates a welcoming experience to Monticello for $97 \%$ of visitors surveyed. $76 \%$ had a very positive impression of the Visitor Center landscape.}

Method: A visitor experience survey was conducted at the Visitor Center on Friday, July 25 (10:30am$1: 30 \mathrm{pm})$ and Saturday, July $26(1: 00 \mathrm{pm}-3: 00 \mathrm{pm})$. These dates and times were at the suggestion of the Thomas Jefferson Foundation staff, to maximize on the highest visitor days of the week, and times when the Visitor Center is the most active. The research team displayed printed surveys at a table within the central courtyard of the Visitor Center. The team intercepted visitors during their visit, focusing on those who were at the end of their visit: either returning from the mountaintop or leisurely sitting around the courtyard.

Data: Total respondents: 138

1. Are you aware that the Visitor Center is a new complex completed in 2009 , which includes the ticket pavilion, museum gift shop, café, and museum exhibition in addition to the outdoor courtyard, lush gardens and Greensward between the courtyard and the African American Graveyard?

YES: $30 \%$

NO: $68 \%$

2. How do you view the Visitor Center outdoor landscape overall?

Very Positive 76\%

Somewhat Positive 22\%

Neutral: $1 \%$

Somewhat Negative: $1 \%$

Negative: $0 \%$

3. Does the outdoor landscape of the Visitor Center (courtyard, fountain, gardens, seating, parking, etc) provide a welcoming experience to Monticello?

YES: $97 \%$

4. Which of the following outcomes of the improvement to the Visitor Center do you feel is most important? (select all that apply)

Shaded outdoor gathering spaces: $65 \%$

The lush gardens of native plants encompassing the Visitor Center: $51 \%$

Improved parking circulation: $34 \%$

Greenroof that helps reduce energy costs: $33 \%$

Gardens that help absorb storm water: $29 \%$

Siting of the Visitor Center close to the forest: $26 \%$

Greensward that leads from the main courtyard to the African American Graveyard, giving it a more dignified setting: $22 \%$ 
Limitations: The survey reached a small fraction of Monticello's annual visitors. Efforts were made to do an online survey to reach more visitors who might remember the conditions before the new Visitor Center in order to gain a broader perspective of the changes to the landscape. However, due to time constraints an intercept survey was determined to be the most efficient way to collect visitor feedback.

\section{Economic Performance Benefits:}

- Contributed to a $19 \%$ increase in retail sales and a $250 \%$ increase in revenue from special events between 2009 and 2013.

Method: Data was collected from the Thomas Jefferson Foundation and their yearly financial records.

Data: According to the Thomas Jefferson Foundation, "The Museum Shop sales earned per visitor went up drastically after the opening in the Visitor Center and they have remained well above previous sales figures since the Visitor Center's opening."

Limitations: Data was not broken down by yearly sales, and therefore detailed year-to-year comparisons could not be made.

\section{Cost Comparison}

- A palette of native plants greatly reduced the need for regular irrigation. According to the LEED documentation, the design requires 292,700 gallons less per year than a baseline case. At a cost of $\$ 6.04$ per 1,000 gallons, the saving adds up to $\$ 1,770$ per year.

Over 20 years, the total savings would be $\$ 35,350$.

Data:

\begin{tabular}{|l|r|}
\hline Baseline Case (July) & $132,560.7 \mathrm{gal}$ \\
\hline Design Case (July) & $49,927.6 \mathrm{gal}$ \\
\hline Savings (July) & $82,633.1 \mathrm{gal}$ \\
\hline Typical irrigation cycles (July) & 24 \\
\hline Average water savings per cycle & $3,443 \mathrm{gal}$ \\
\hline Total typical cycles per year & 85 \\
\hline Total average water savings/year & $292,659 \mathrm{gal}$ \\
\hline $\begin{array}{l}\text { Total average water savings/year } \\
(1000 \text { gal) }\end{array}$ & 293 \\
\hline Cost/1000 gal & $\$ 6.04$ \\
\hline Annual cost savings & $\mathbf{\$ 1 , 7 6 7 . 6 6}$ \\
\hline
\end{tabular}

\section{Sustainable Feature}

- Use of the existing infrastructure, parking, and vehicular circulation resulted in limited site disturbance. 140,458 sf of asphalt (82\% of the existing parking lot) was incorporated into the new lot design so that only 30,517 sf of new asphalt was added to create 104 additional spaces. 
Method: The research team used drawings to calculate square footage of the asphalt removed, reused and created. The end result of the parking lot transformations is 410 car parking spaces, and 20 bus/RV parking spaces.

\section{Data:}

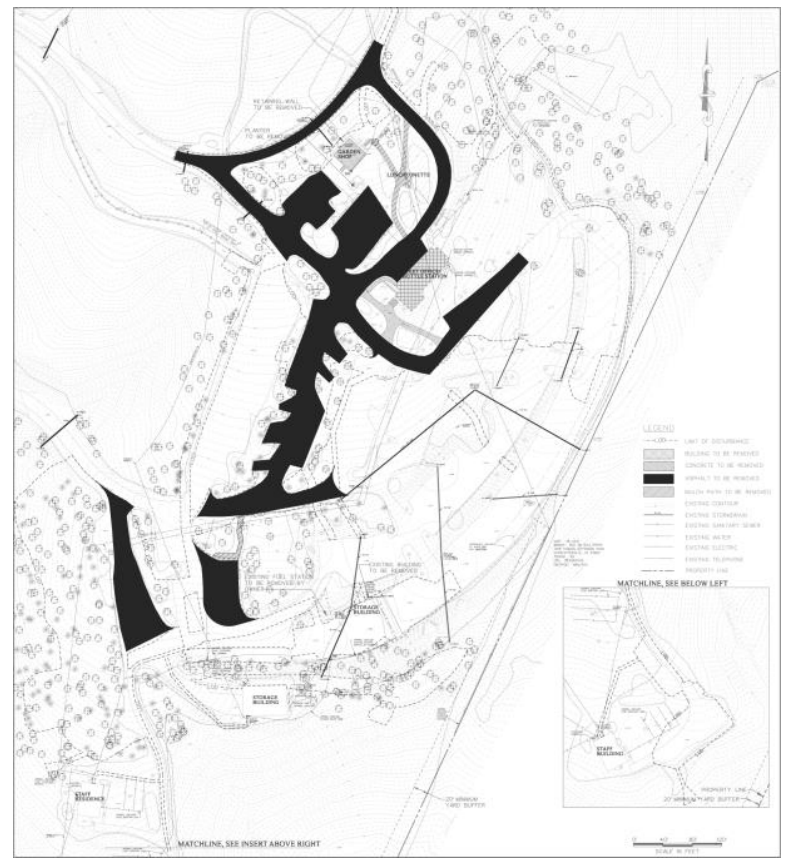

Figure 4. Site demolition plan highlighting removed asphalt in black

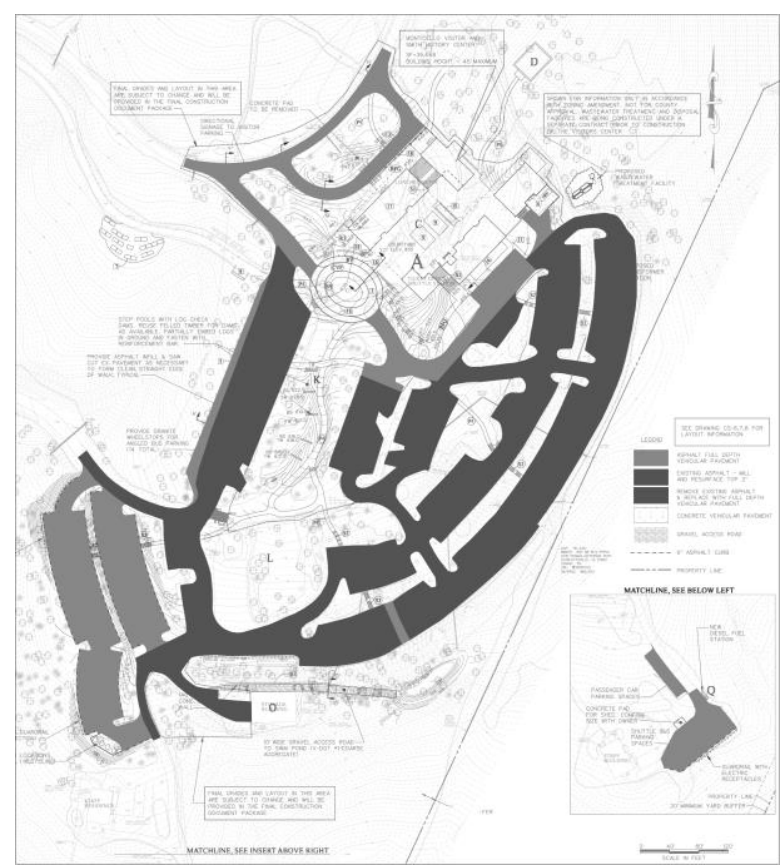

Figure 5. Site and grading plan showing reused asphalt in dark grey and added asphalt in light grey

\section{Combined References:}

Michael Vergason Landscape Architects, Ltd. "Irrigation Cost Savings." 2009.

Michael Vergason Landscape Architects, Ltd. "LEED-NC 2.2 Submittal Template WE Credit 1: Water Efficient Landscaping." LEED-NC. 2009.

Thomas Jefferson Foundation. Overall Visitor Satisfaction Index. Charlottesville: 2014.

Thomas Jefferson Foundation. Special Events List of the Thomas Jefferson Visitor Center. Charlottesville: 2014.

Thomas Jefferson Visitor Center LEED-NC: Construction Application Review. : U.S. Green Building Council, 2009. 